\title{
Reprogrammed mouse astrocytes retain a "memory" of tissue origin and possess more tendencies for neuronal differentiation than reprogrammed mouse embryonic fibroblasts
}

\author{
Changhai Tian ${ }^{1,2}$, Yongxiang Wang ${ }^{1,2}$, Lijun Sun ${ }^{1,2}$, Kangmu Ma ${ }^{1,2}$, Jialin C. Zheng ${ }^{1,2,3 凶}$ \\ ${ }^{1}$ Laboratory of Neuroimmunology and Regenerative Therapy, University of Nebraska Medical Center, Omaha, NE 68198-5930, \\ USA \\ 2 Departments of Pharmacology/Experimental Neuroscience, University of Nebraska Medical Center, Omaha, NE 68198-5930, \\ USA \\ ${ }^{3}$ Departments of Pathology/Microbiology, University of Nebraska Medical Center, Omaha, NE 68198-5930, USA \\ $\triangle$ Correspondence: ctian@unmc.edu (C. Tian), jzheng@unmc.edu (JC. Zheng) \\ Received January 15, 2011 Accepted January 20, 2011
}

\section{ABSTRACT}

Direct reprogramming of a variety of somatic cells with the transcription factors Oct4 (also called Pou5f1), Sox2 with either KIf4 and Myc or Lin28 and Nanog generates the induced pluripotent stem cells (iPSCs) with marker similarity to embryonic stem cells. However, the difference between iPSCs derived from different origins is unclear. In this study, we hypothesized that reprogrammed cells retain a "memory" of their origins and possess additional potential of related tissue differentiation. We reprogrammed primary mouse astrocytes via ectopic retroviral expression of OCT3/4, Sox2, KIf4 and Myc and found the iPSCs from mouse astrocytes expressed stem cell markers and formed teratomas in SCID mice containing derivatives of all three germ layers similar to mouse embryonic stem cells besides semblable morphologies. To test our hypothesis, we compared embryonic bodies (EBs) formation and neuronal differentiation between iPSCs from mouse embryonic fibroblasts (MEFsiPSCs) and iPSCs from mouse astrocytes (mAsiPSCs). We found that mAsiPSCs grew slower and possessed more potential for neuronal differentiation compared to MEFsiPSCs. Our results suggest that mAsiPSCs retain a "memory" of the central nervous system, which confers additional potential upon neuronal differentiation.

KEYWORDS mouse astrocytes, induced pluripotent stem cells, neural progenitor cells, neuronal differentiation

\section{INTRODUCTION}

Induced pluripotent stem cells (iPSCs), the direct reprogramming of differentiated somatic cells to pluripotency, were accomplished in 2006 by Takahashi and Yamanaka via the introduction of a select group of transcription factors into adult mouse fibroblasts (Takahashi and Yamanaka, 2006). In 2007, direct reprogramming was also achieved in human cells, providing an invaluable contribution to the field of regenerative medicine (Takahashi et al., 2007; Yu et al., 2007). So far, a variety of cell types have been reprogrammed into iPSCs including fibroblasts (Takahashi and Yamanaka, 2006; Takahashi et al., 2007; Yu et al., 2007), neural progenitor cells (NPCs) (Kim et al., 2008, 2009a, 2009b, 2009c), hepatocytes and gastric epithelial cells (Aoi et al., 2008), CD34+ T cells (Ye et al., 2009), B cells (Hanna et al., 2008; Pereira et al., 2008), pancreatic $\beta$ cells (Stadtfeld et al., 2008), melanocytes (Utikal et al., 2009) and keratinocytes (Aasen et al., 2008; Carey et al., 2009). Although these iPSCs exhibit a similarity with embryonic stem cells (ESCs) in their morphology, gene expression profile and pluripotency, new evidence showed substantial molecular and functional differences among iPSCs derived from distinctive cell types exist including the tumorigenic potential, DNA methylation and expression of imprinted genes, suggesting an influence of the somatic cell of origin on the properties of resultant iPSCs (Ghosh et al., 2010; Polo et al., 2010).

Recently, it was reported that reprogrammed somatic cells harbor residual DNA methylation signatures characteristic of their somatic tissue of origin, called a "memory" of their 
origins, which favors their differentiation along lineages related to the donor cells (Hu et al., 2010; Kim et al., 2010; Polo et al., 2010). Astrocytes are the most common type of cell in the central nervous system (CNS), genetically similar to other neuronal lineages and play important roles in maintaining the physical structuring of the brain, providing neurons with nutrients, maintaining the integrity of the blood brain barrier (BBB), regulating transmitter reuptake and release, as well as nervous system repair and neurogenesis (Blackburn et al., 2009). NPCs have been directly reprogrammed into iPSCs through the ectopic expression of Oct4 alone or Oct4 and Klf4 (Kim et al., 2008, 2009a, 2009b). However, the reprogramming of astrocytes and the differences between iPSCs from CNS and from fibroblasts have not been well investigated.

In this study, we developed iPSCs from mouse astrocytes and evaluated their similarity to mouse ESCs. We also compared the propensity for neuronal differentiation of mouse astrocyte-derived iPSCs (mAsiPSCs) with mouse embryonic fibroblasts (MEFs)-derived iPSCs. We found that mouse astrocytes required four transcription factors to accomplish the reprogramming into pluripotent status. Moreover, reprogrammed mouse astrocytes expressed stem cell markers and formed teratomas in SCID mice containing derivatives of all three germ layers, similar to mouse embryonic stem cells besides semblable morphologies. Furthermore, reprogrammed mouse astroyctes retain a "memory" of tissue of origin and possess more potential for neuronal differentiation compared to MEFs-derived iPSCs.

\section{RESULTS}

\section{Reprogramming mouse astrocytes to iPSCs}

Reprogramming of adult mouse astrocytes to pluripotency was determined by packaging retroviruses containing transcription factors Oct3/4, Sox2, Klf4 and c-Myc, respectively, incubating mouse astrocytes with different combinations of transcription factors including Oct $3 / 4+$ Sox $2+\mathrm{Klf} 4+\mathrm{Myc}$ (TF4, 1:1:1:1), Oct3/4 + Sox2 + Klf4 (TF3, 1:1:1), Oct3/4 + Sox2 (1:1) and Sox2 + KIf4 (1:1), and then following the timeline of iPSC generation (Fig. 1A). One week later, colonies only appeared in the cultures with four transcription factors (TF4) (Fig. 1B (a)), not in the cultures with other combinations of transcription factors (data not shown). After

A

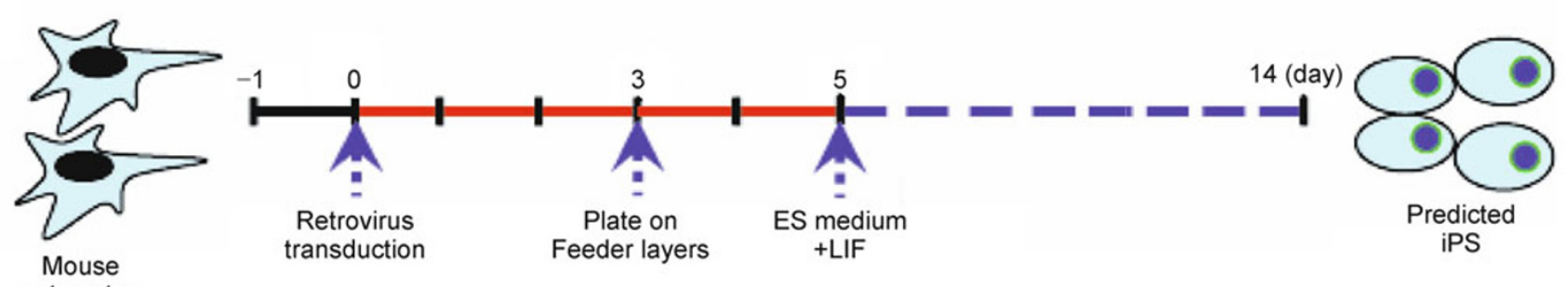

B
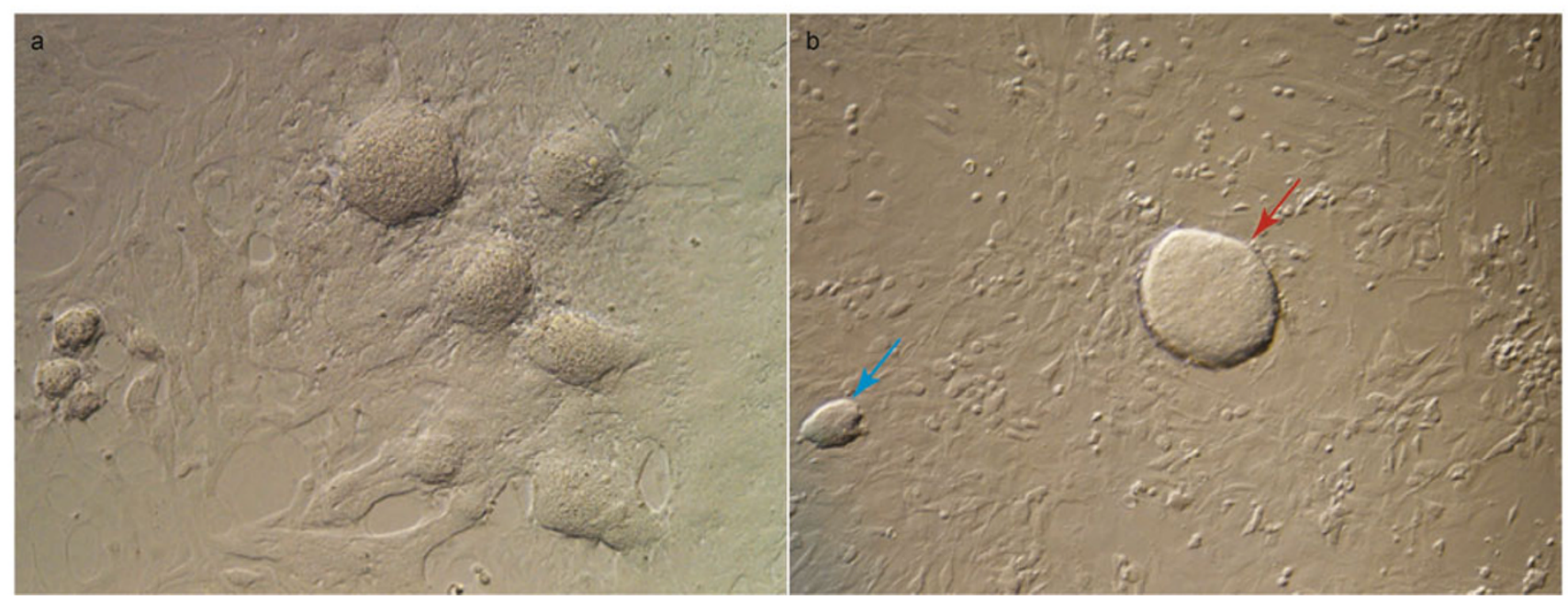

Figure 1. Generation of iPSCs from mouse astrocytes. (A) General scheme of iPS cell generation. (B) Astrocytes isolated from the brain of embryonic day $13.5 \mathrm{C} 57 \mathrm{BL} / 6$ embryos were infected by retroviruses containing oct3/4, sox 2 , klf4 and c-myc at day 0 , and then plated on feeder layers at day 3 after retroviral infection. ES cell medium containing leukemia inhibitory factor (LIF) was changed at day 5 until the colonies were formed at day 14 (b), arrows indicating the clones from astrocytes. 
these colonies were passaged onto feeder cells, the cells formed embryonic body-like morphologies (Fig. 1B (b)). The embryonic body-like colonies were evaluated by analyzing the alkaline phosphatase (AP) activity and the expression of mouse ES cell markers including Nanog and SSEA-1 immunocytochemically. Our results demonstrated that the iPSCs from mouse astrocytes not only exhibited a morphology similar to that of mouse ES cells (Fig. 2), but also possessed the same AP activity (Fig. 2B; upper panel) and expression profiles of Nanog and SSEA-1 as mouse ES cells (Fig. 2B; lower panel). These data suggest that unlike neural progenitor cells, mouse astrocytes require four transcription factors to accomplish the reprogramming to pluripotent state, and reprogrammed mouse astrocytes have similar properties to mouse ES cells in both morphology and marker protein expression.

\section{Teratoma formation by mAsiPSCs}

The capacity of mAsiPSCs to differentiate into the three germ layers in teratoma was assessed by transplant of mouse ESCs and mAsiPSCs subcutaneously into each flank of recipient NOD/SCID mice. After 3-5 weeks, tumor formation was observed in both of ES cells and mAsiPSCs injection sides (Fig. 3A) and histological examination results showed that the teratomas from mAsiPSCs contained tissues from three primary germ layers (Fig. 3B), including neural epithelium and epidermis (ectoderm; left panel), muscle and cartilage (mesoderm; middle panel), and respiratory epithelium and intestinal epithelium (endoderm; right panel). These histological results were similar to that of mouse ES cells (data not shown), suggesting that the iPSCs reprogrammed from mouse astrocytes exhibit pluripotency in vivo.

\section{Differentiation of mAsiPSCs into neural progenitor cells and neurons}

It must be possible to control the differentiation of stem cells into specific cell fates, thus demonstrating the developmental transitions of stem cells and how they fulfill their clinical promise. The capacity of mAsiPSCs to differentiate into neural progenitor cells and neurons in vitro was evaluated by expanding the undifferentiated mAsiPSCs population on gelatin-coated tissue culture surface in ES cell culture medium in the presence of leukemia inhibitory factor (LIF) and generated EBs in suspension cultures, and then selecting nestin-positive cells in serum-free ITSFn (Insulin/ Transferrin/Selenium/Fibronectin) medium. After cell expansion, we identified the percentage of nestin-positive cell population and subsequently detected the neuronal differentiation of nestin-positive cells (Fig. 4). Our results demonstrated that more than $90 \%$ cells were nestin-positive cells (Fig. 4A; upper panel), which were totally differentiated into neurons (MAP-2 positive) after 7 days differentiation (Fig. 4A; lower panel). Western blotting analysis further confirmed that the population of neurons was increased in a time-dependent manner and was accompanied with the decrease of nestinpositive cells (Fig. 4B). These data suggest that mAsiPSCs can be normally differentiated into neural progenitor cells and neurons, which is similar to the differentiation capacities of mouse ES cells.

Mouse ES cells have been successfully differentiated into CNS progenitor populations and further differentiated into dopaminergic and serotonergic neurons in the presence of mitogen and specific signaling molecules (Lee et al., 2000; Wakayama et al., 2001). In general, neural stem cells (NSCs) lose their competency to generate region-specific neuronal populations at an early stage during embryonic brain development. So we proposed the NSCs derived from mAsiPSCs possess this competency to generate regionspecific neuronal populations, such as dopaminergic neurons (DA neurons). To test this competency of NSCs from mAsiPSCs, we differentiated mAsiPSC-derived NSCs into dopaminergic neurons by removal of the mitogen in the differentiation medium. 7 days later, the morphologies of mature neurons were observed in cultures (Fig. 5A). The expression of tyrosine hydroxylase $(\mathrm{TH})$, the rate-limiting enzyme for the biosynthesis of dopamine and a marker of ventral midbrain neurons, was not detected before the removal of mitogen in the differentiation medium (data not shown). However, $\mathrm{TH}^{+}$cell differentiation was promoted under conditions known to promote neuronal differentiation from the proliferating precursor state (VicarioAbejón et al., 1995; Johe et al., 1996; Studer et al., 1998). Tuj1, an antibody directed against the neuron-specific $\beta$-tubulin III, bound many cells with a clear neuronal morphology (Fig. 5B). Of the total cell population, more than $80 \%$ were Tuj $1^{+}$, and about $8 \%$ of the Tuj $1^{+}$cells were also $\mathrm{TH}^{+}$. Moreover, real-time PCR results further demonstrated that the population of $\mathrm{TH}^{+}$was gradually increased in a time-dependent manner (Fig. 5C), suggesting that the mAsiPSC-derived nestin-positive population is dominated by CNS stem cells and can be differentiated into midbrain neurons.

\section{mAsiPSCs have a higher tendency to differentiate into region-specific neurons compared to MEFsiPSCs}

Recent studies have shown that nuclear transferred ESCs and transcription factor-induced pluripotent stem cells exhibit differences in differentiation potential, which might be because iPSCs retain a certain amount of DNA methylation profile and gene expression patterns traceable to their tissue of origin (Kim et al., 2010; Polo et al., 2010). In addition, astrocytes are the most common type of cell in the CNS, genetically similar to other neuronal lineages (Blackburn et al., 2009). Therefore we asked if the mAsiPSCs possess higher potential for differentiation into region-specific neurons compared to MEFsiPSCs. To address this question, we 
did the comparison of cell proliferation and neuronal differentiation between mAsiPSCs and MEFsiPSCs. First, the same amount of iPSCs was cultured in suspension in bacteriological graddishes. We observed that the EB size of low-passage mAsiPSC clone (mAsiPSCs No. 40) was smaller than that of MEFsiPSCs and mouse ESCs, and there was no difference between MEFsiPSCs and mouse ESCs (Fig. 6), suggesting that low-passage mAsiPSCs proliferate slower than the other two stem cells. When MEFsiPSCs and mAsiPSCs were subjected to the expansion of nestin-positive cells and differentiation by using a modified protocol (Lee et al., 2000), we found that nestin-positive cells in both of them were close to $100 \%$ and no obvious difference existed between them (Fig. 7A). However, when these nestinpositive cells were subjected to the differentiation of regionspecific neurons, we found that the population of NPCs from mAsiPSCs not only had more neurons with well-developed dendrites (Fig. 7B), but also possessed higher potential for differentiation into dopaminergic neurons compared to MEFsiPSCs in a time-dependent manner (Fig. 7C). These results suggest reprogrammed mouse astrocytes may retain the epigenetic imprints of their tissue of origin, which endows $\mathrm{mAsiPSC}$ with more potential for region-specific differentiation.

A
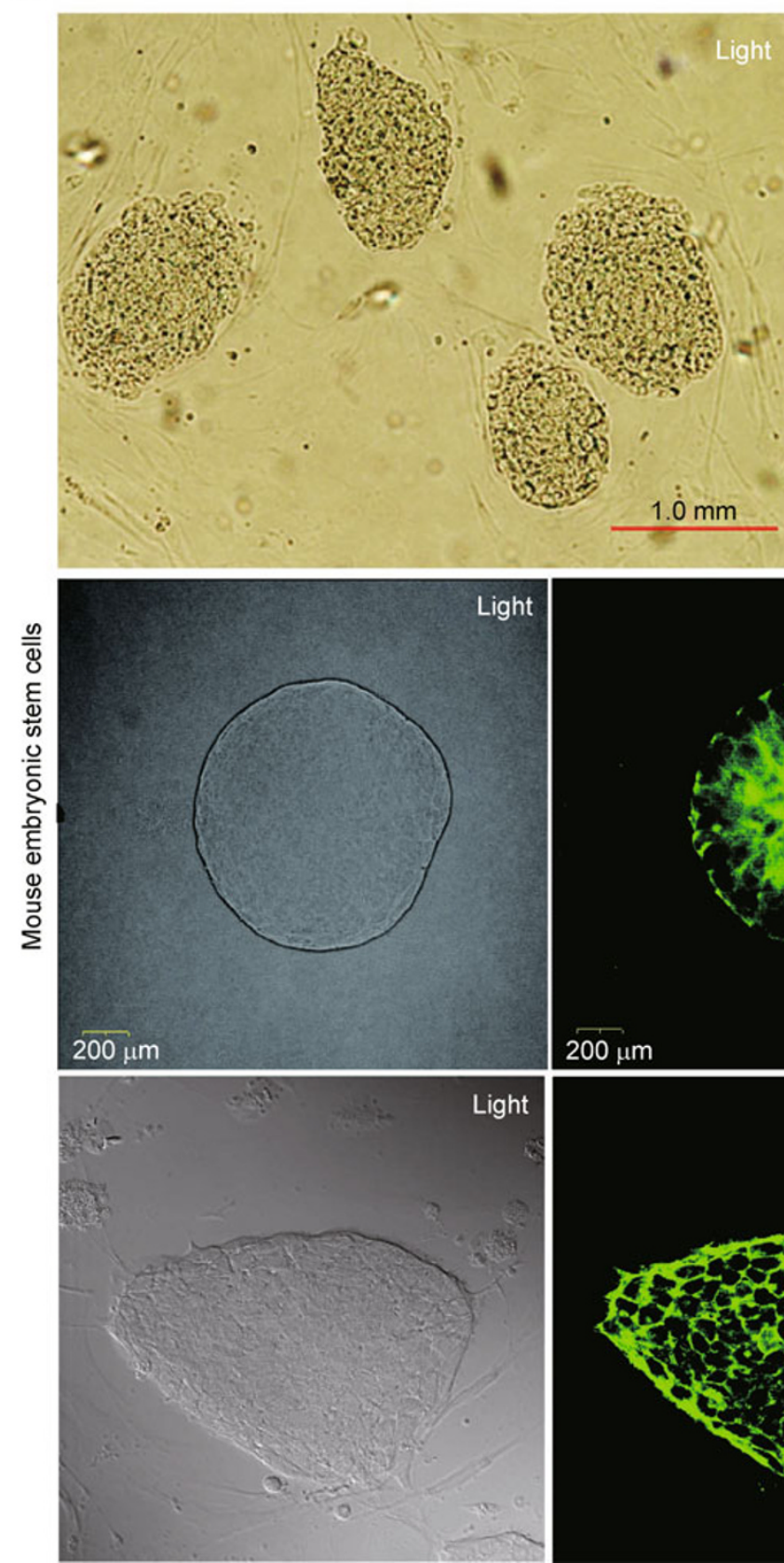

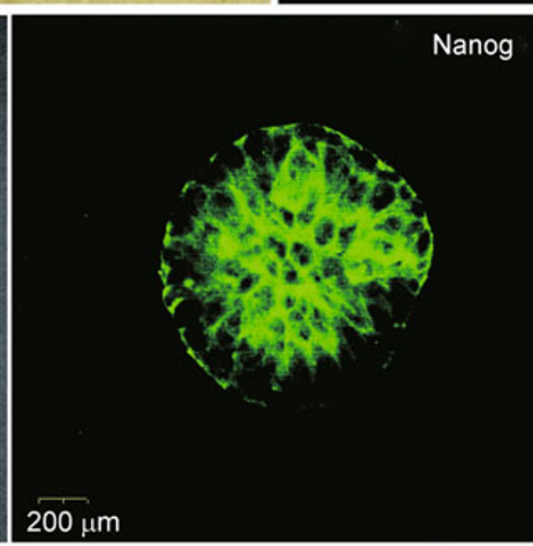

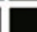

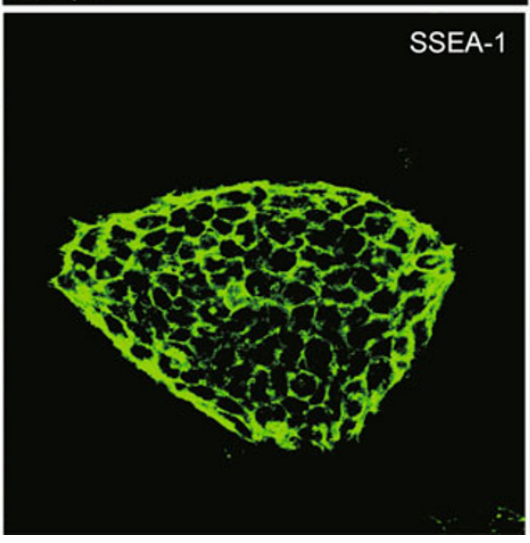

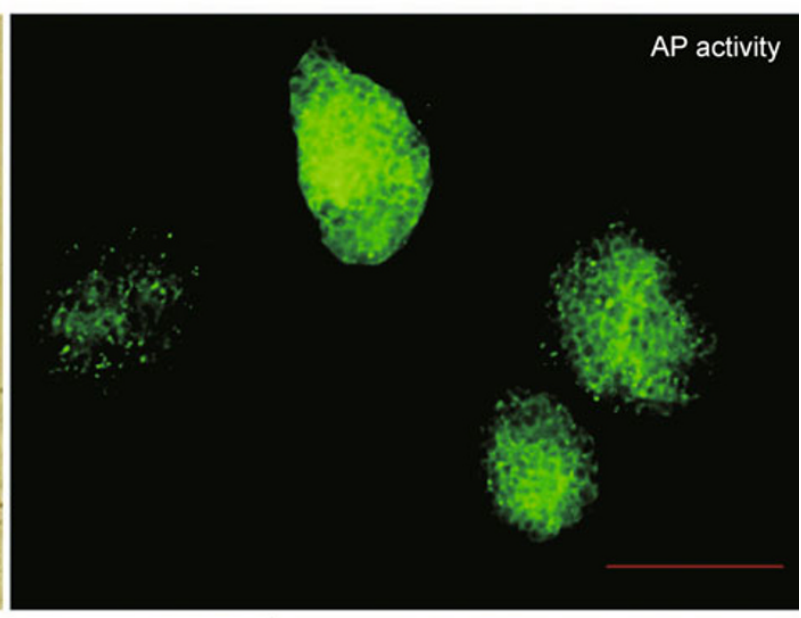

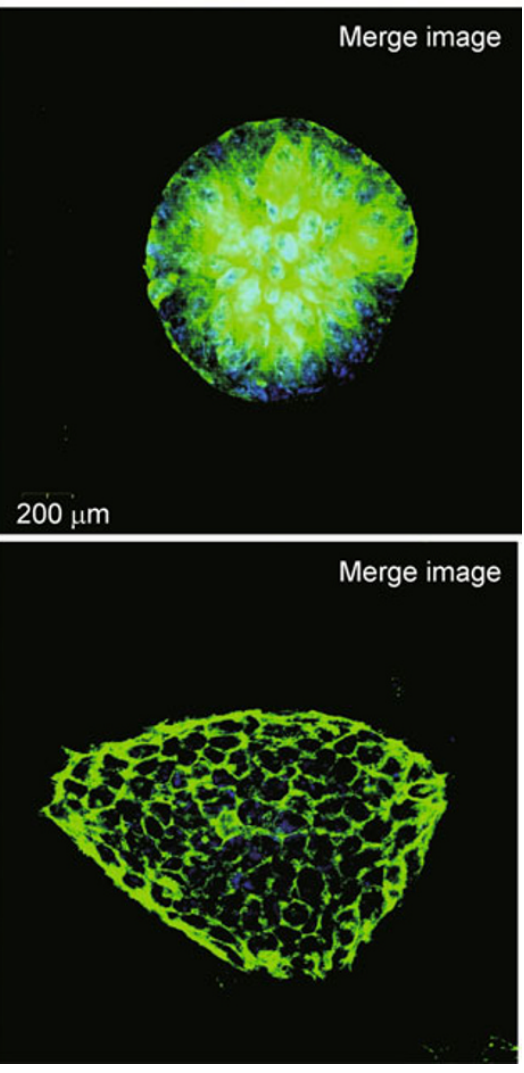


B
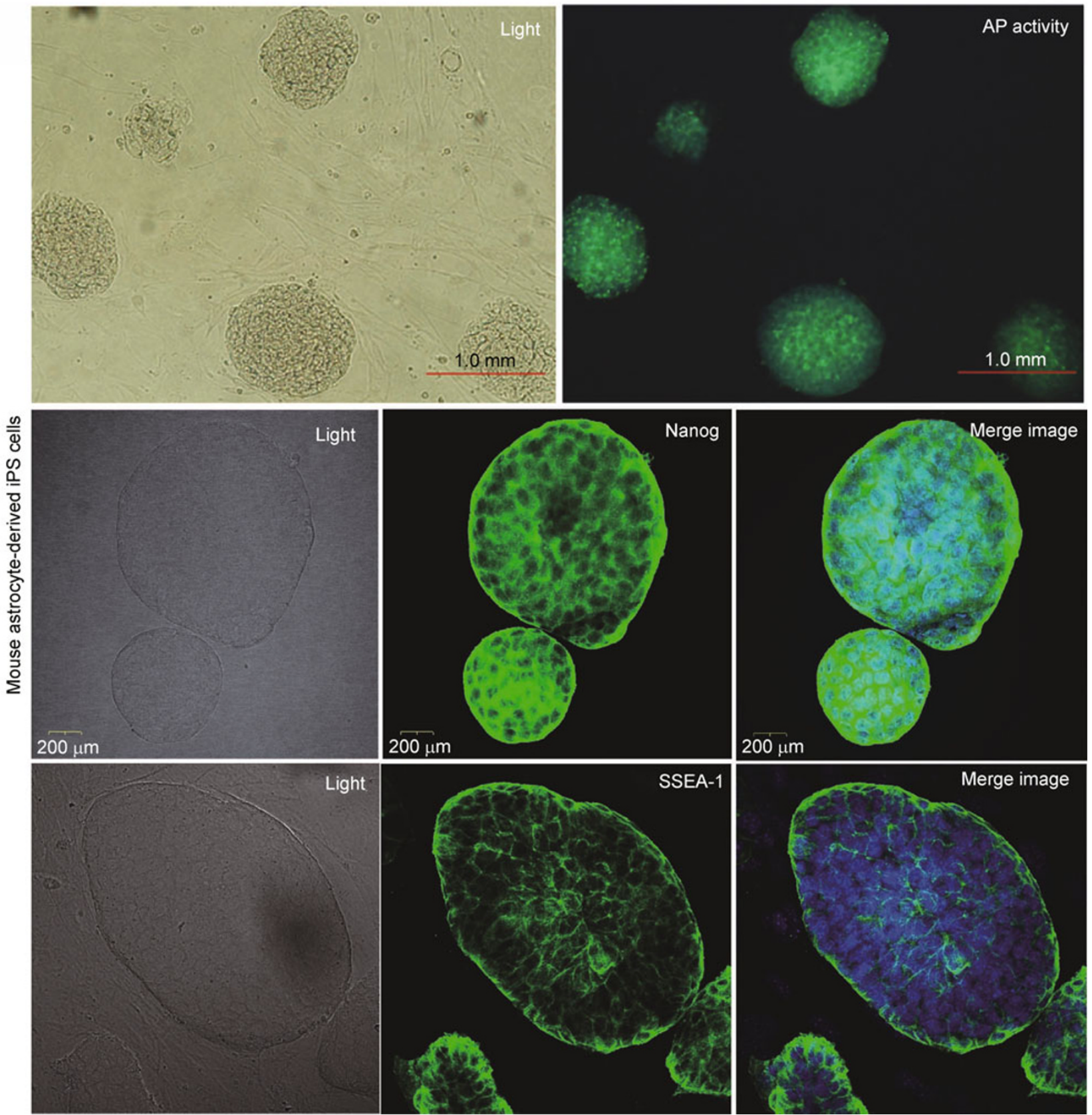

Figure 2. Characterization of mouse ES cells and mouse iPSCs derived from mouse astrocytes. Mouse ESCs (A) and mouse iPSCs derived astrocytes (B) were plated onto feeder cells, which were cultured on $0.1 \%$ gelatin-coated coverslips. After culturing with mouse ES cell culture medium for five days, cells were fixed with $4 \%$ formaldehyde, and then subjected to alkaline phosphatase (AP) activity analysis, following the instruction manual of ELF® Phosphatase Detection Kit for Embryonic Stem Cells (ATCC, SCRR-3010). The upper right panel is light morphology of embryonic bodies, and the upper left panel (yellow-green embryonic bodies) indicates AP activity $(20 \times)$ (A, B; upper panel). Cells fixed with $4 \%$ formaldehyde were subjected to immunofluorescence staining with polyclonal Nanog antibody and SSEA-1 monoclonal antibody (Green) and nuclear staining with DAPI (Blue) (A, B; lower panel).

\section{DISCUSSION}

This study demonstrates that adult mouse astrocytes can be reprogrammed into iPS cells by using four transcription factors (Yamanaka factors) including Oct3/4, Sox2, Klf4 and c-Myc. The iPS cell lines derived from mouse astrocytes 
A
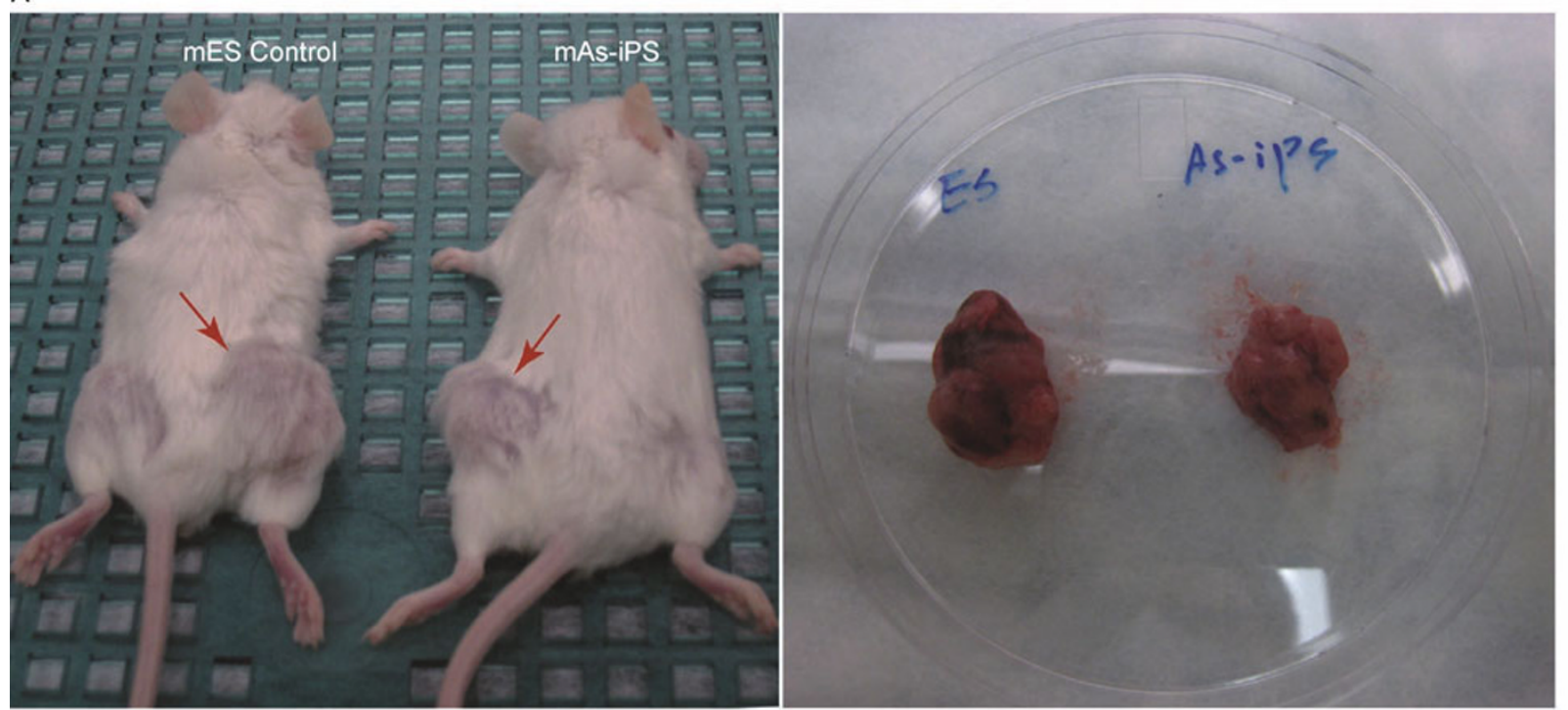

B
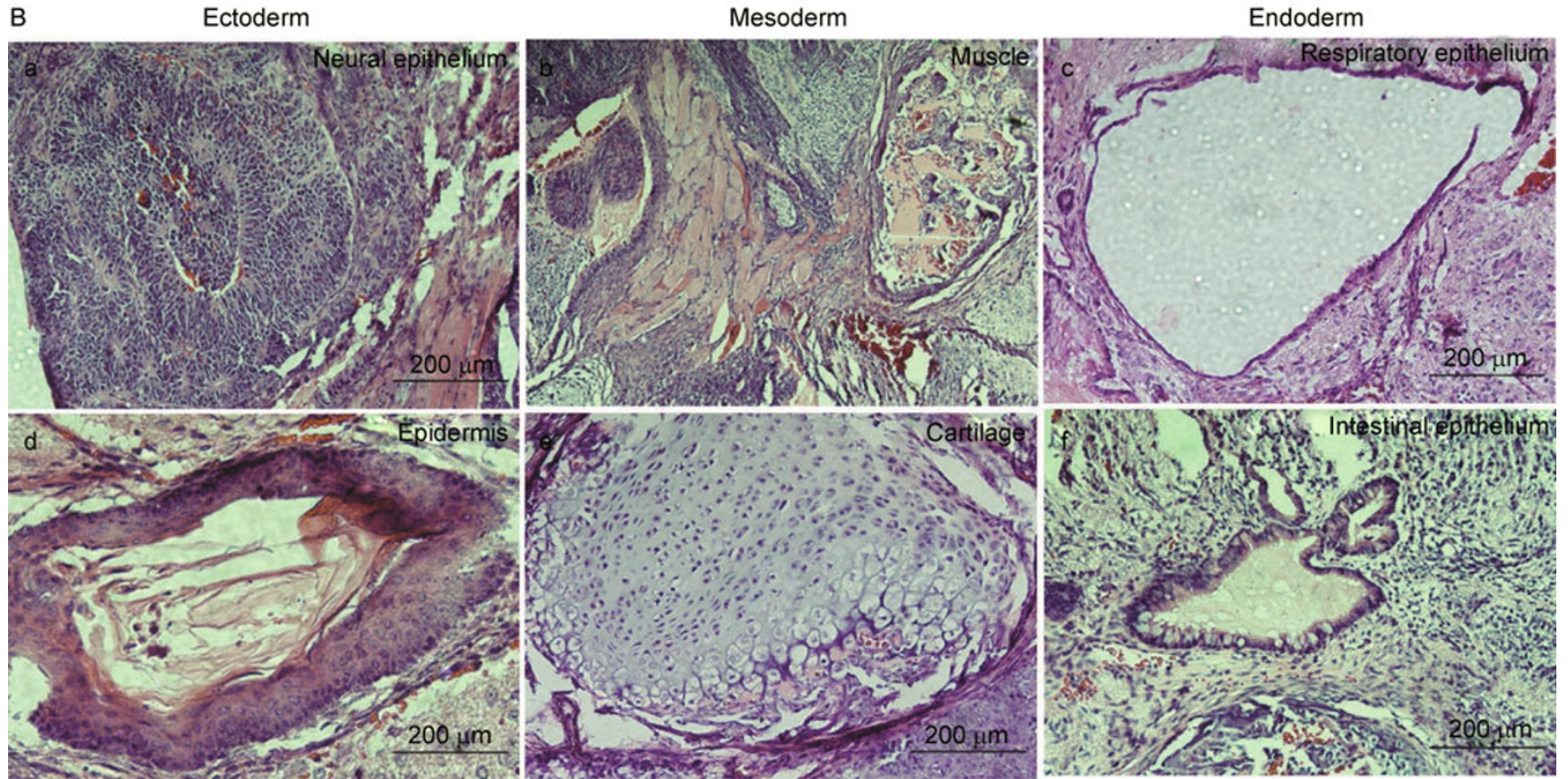

Figure 3. Teratoma from mouse ESCs and mAsiPSCs in severe combined immunodeficiency (SCID) mice. $1 \times 10^{6}$ mouse ES cells and mAsiPSCs were injected subcutaneously into the dorsal flank of SCID mice (Jackson Laboratory, Bar Harbor, ME). (A) The teratomas were formed in 3-5 weeks after cell injection in SCID mice. (B) Paraffin sections of formalin-fixed teratoma specimens were prepared 3-5 weeks after injection, and hematoxylin and eosin staining shows a teratoma from mouse astrocyte-derived iPS cells containing multiple tissues. Higher magnification pictures show neural epithelium (a), muscle (b), respiratory epithelium (c), epidermis (d), cartilage (e) and intestinal epithelium (f). Scale bar, $200 \mu \mathrm{M}$.

express markers of pluripotency, can form teratomas in vivo containing three different germ layers and can normally differentiate into different neuronal lineages in vitro. In addition, mAsiPS cell lines can be more easily induced into region-specific neurons than MEFsiPSCs. It has been reported that iPSCs were successfully generated from mouse and human fibroblasts (Takahashi and Yamanaka, 2006; Takahashi et al., 2007; Yu et al., 2007), neural progenitor cells (Kim et al., 2008, 2009a, 2009c), hepatocytes and gastric epithelial cells (Aoi et al., 2008), CD34+ T cells (Ye 
A

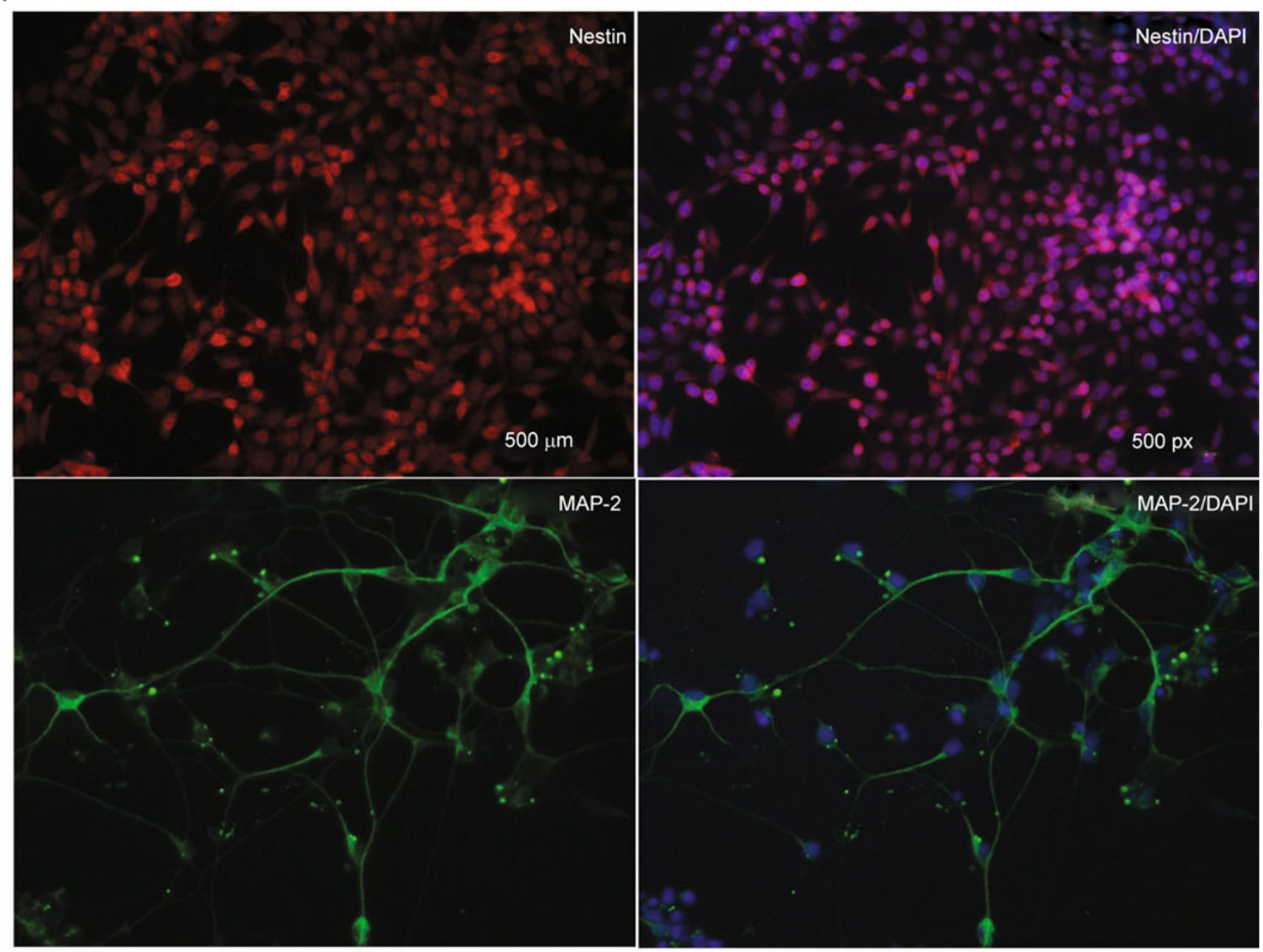

B 0 3 5 7 (day)

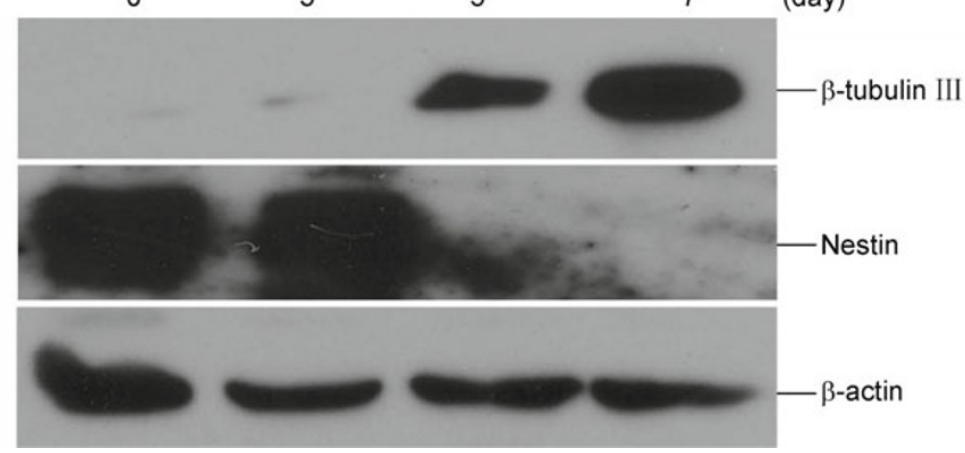

Figure 4. mAsiPSCs progressively differentiate into neural progenitor cells and neurons. Undifferentiated mAsiPSCs were grown on gelatin-coated tissue culture plates in the presence of leukemia inhibitory factor (LIF, GIBCO/BRL, Grand Island, NY) in ES cell medium until embryonic bodies (EBs) were formed. The EBs were then plated onto adhesive tissue culture surface in the ES cell medium and changed to serum-free Insulin/Transferrin/Selenium/Fibronectin (ITSFn) medium to screen nestin-positive cells after $24 \mathrm{~h}$. After 6-10 days culture in ITSFn medium, the cells were plated on collagen IV-coated coverslips and then subjected to immunostaining with monoclonal nestin antibody (Red) and nuclear staining with DAPI (Blue) (A; upper panel). The cells cultured on collagen IV-coated coverslips were incubated under neuronal differentiation conditions for 7 days, and then subjected to immunostaining with monoclonal MAP-2 antibody (Green) and nuclear staining with DAPI (Blue) (A; lower panel). Nestin-positive cells were cultured on collagen IV-coated 24-well plates, and then cultured under neuronal differentiation conditions for $0,3,5$ and 7 days, respectively, and finally subjected to Western blotting analysis with nestin, $\beta$-tubulin III antibodies, and $\beta$-actin as a loading control (B). 
A

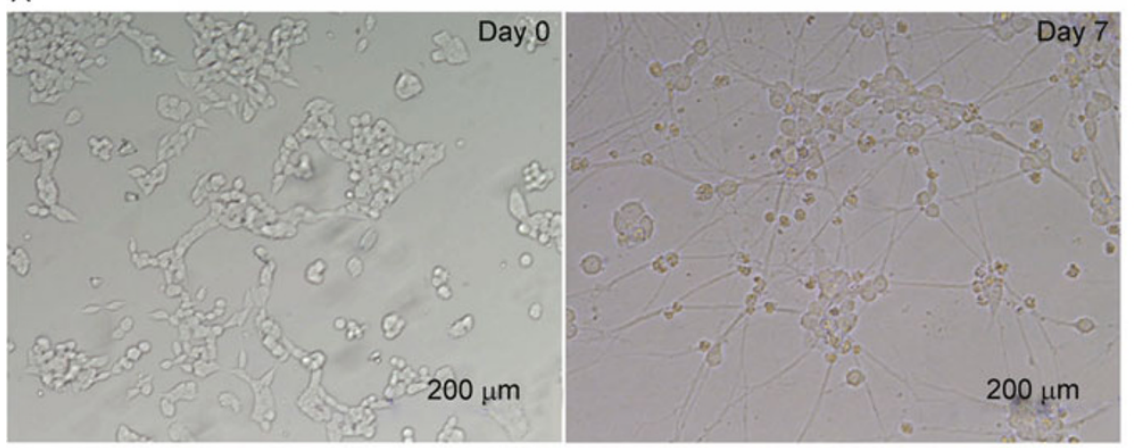

B

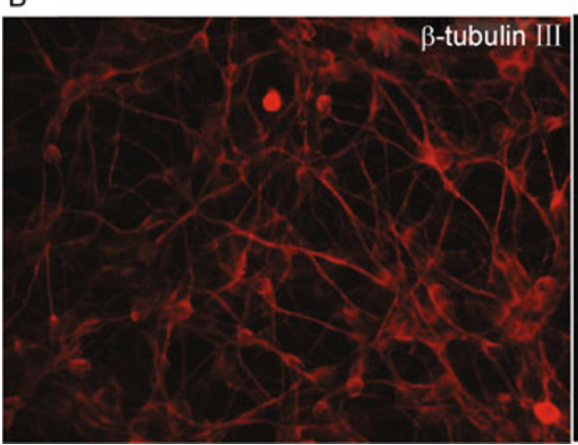

C

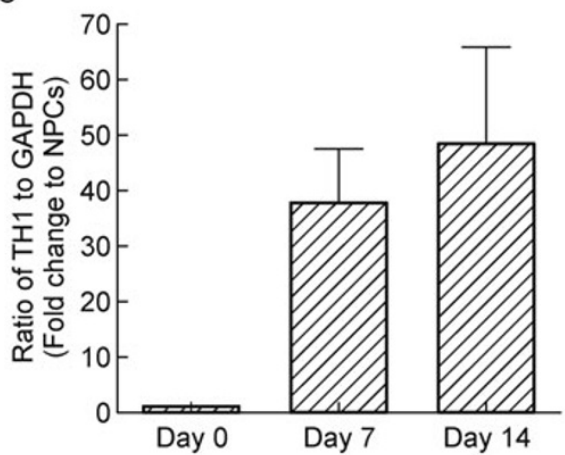

Figure 5. Dopaminergic (DA) neuron differentiation of mAsiPSC-derived neural progenitor cells (NPCs). Nestin-positive cells from mAsiPSCs were plated on collagen IV-coated coverslips. And cells were cultured in NPC expansion medium containing $\mathrm{N}_{2}$, $\mathrm{SHH}$ and fibroblast growth factor 8 (FGF8) at day 0 and in DA neuron differentiation medium containing $\mathrm{N}_{2}$ and ascorbic acid (AA) at day 4 . The cells were cultured for another 3 days and fixed with $4 \%$ formaldehyde at day 7 and then subjected to immunostaining with monoclonal tyrosine hydroxylase (TH1) (Green) and polyclonal $\beta$-tubulin III (Red) antibodies and nuclear staining with DAPI (Blue) (B). (A) shows the light morphology of neuronal differentiation. Scale bar, $200 \mu \mathrm{M}$. Cells cultured in DA neuron differentiation medium were collected at 0,7 th and 14th days and then subjected to total mRNA extraction and real-time PCR analysis with mouse TH1 specific primers $(C)$.

et al., 2009), B cells (Hanna et al., 2008; Pereira et al., 2008), pancreatic $\beta$ cells (Stadtfeld et al., 2008), melanocytes (Utikal et al., 2009) and keratinocytes (Aasen et al., 2008; Carey et al., 2009). Therefore, mouse astrocytes may be added to the growing list of somatic cell types that can be reprogrammed to pluripotency.

Both neural progenitor cells and astrocytes are from the CNS, and neural progenitor cells have been reprogrammed to iPSCs by ectopic expression of either Oct4 alone or Oct4 plus Klf4 (Kim et al., 2009a, 2009b, 2009c). We tried different combinations of four transcription factors in order to see if two or three factors are sufficient to reprogram mouse astrocytes (Fig. 1). However, only the combination of all four factors together could accomplish the reprogramming of astrocytes, and two or three factors were not sufficient to perform this process. Comparing the endogenous expression of four transcription factors (Oct3/4, Sox2, Klf4 and c-Myc) between mouse astrocytes and neural progenitor cells, we found the levels of Sox2 and c-Myc were higher in neural progenitor cells (data not shown), which could be one of the reasons that Oct4 alone or Oct4 plus KIf4 can reprogram neural progenitor cells into pluripotency, but is not sufficient for astrocyte reprogramming. These results suggest that different combinations of transcription factors are needed as a minimum requirement to dedifferentiate certain types of cells. Astrocytes are the most common type of cells in the CNS, genetically similar with other neuronal lineages and play important roles in maintaining the physical structuring of the brain, providing neurons with nutrients, maintaining the integrity of the BBB, regulating the transmitter reuptake and release, as well as nervous system repair and neurogenesis (Blackburn et al., 2009). Although astrocytes secrete important neurotrophic factors, cytokines, and chemokines, which may promote CNS recovery from injury, excessive astrogliosis has been shown to cause neuronal damage and neurodegeneration (Fawcett, 1997; Ridet et al., 1997; Hirsch et al., 2003; Rodríguez et al., 2009). Recently, mouse astrocytes have been dedifferentiated into neural progenitor cell-like cells by ectopic expression of the polycomb group proteins (Moon et al., 2008; Sher et al., 2010). However, it was unclear whether these neural stem cell-like cells can function as multipotent NSCs in vivo or whether the polycomb group proteins can generate multipotent NSCs from mouse astrocytes. In general, one of the fundamental questions in 


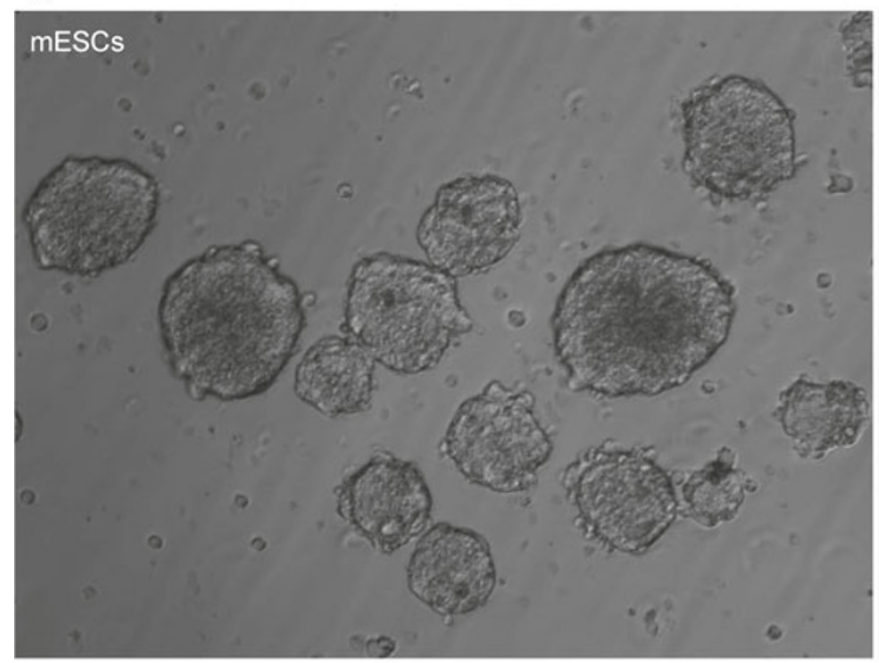

C

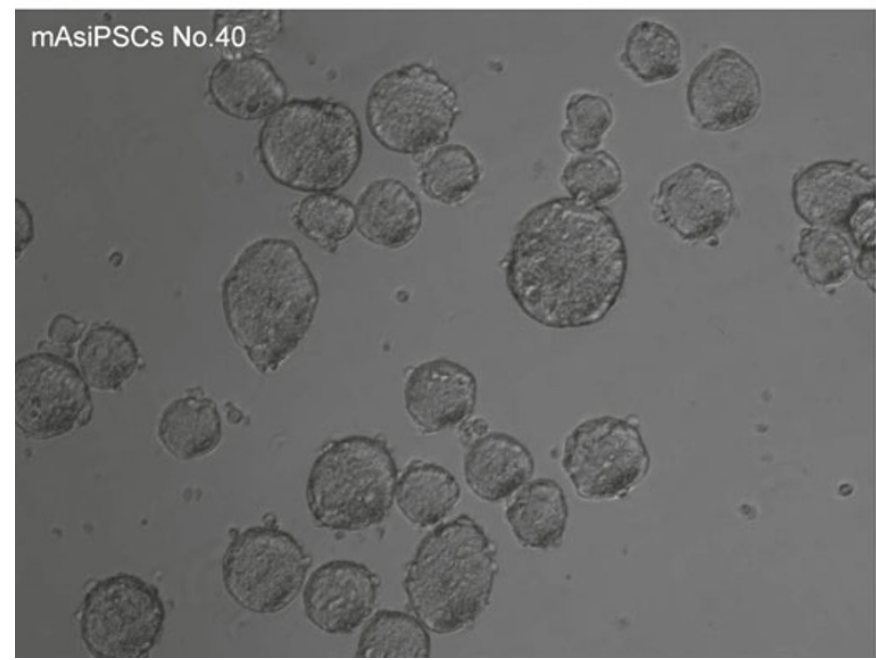

B

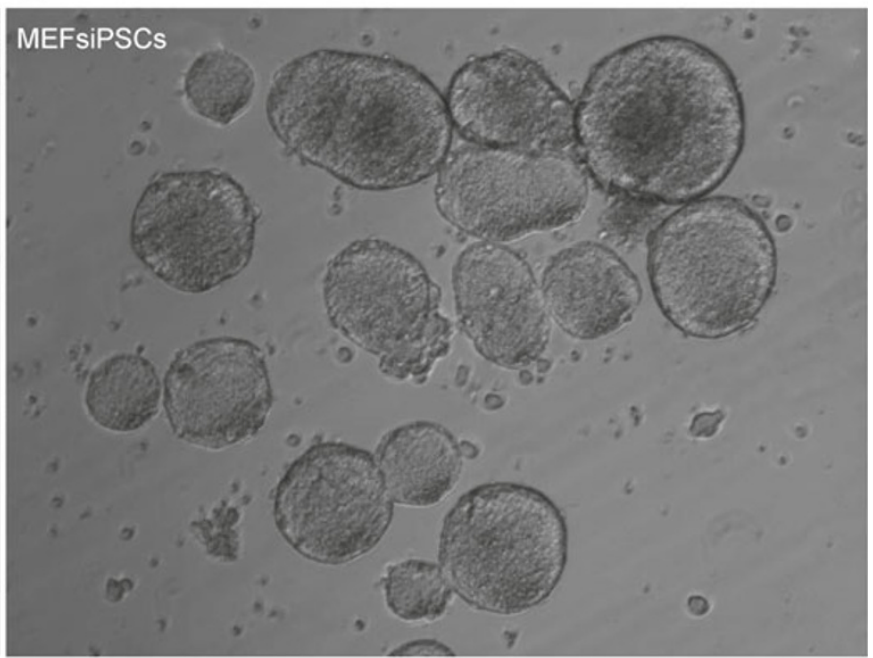

D

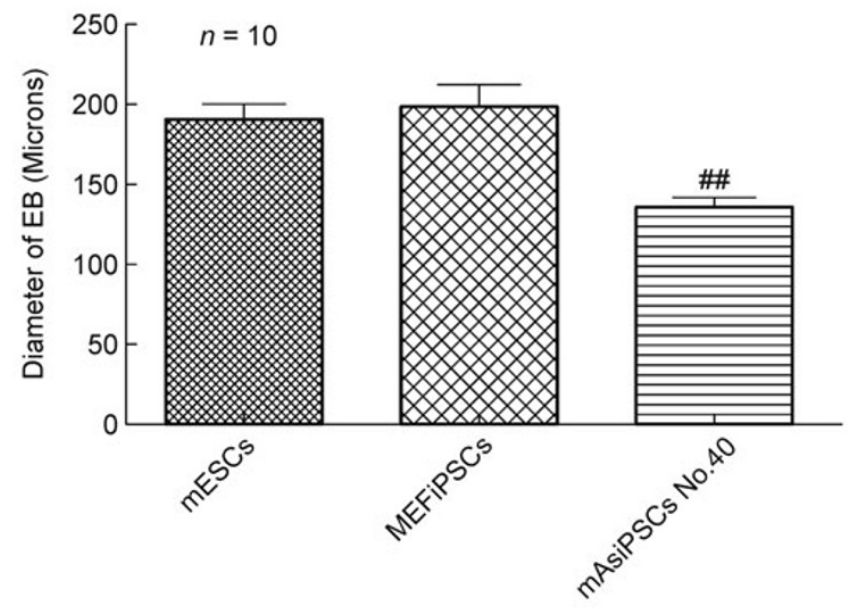

Figure 6. Comparison of EB size between mouse ES cells, MEFsiPSCs and mAsiPSCs. Cells were cultured with ES-DMEM containing leukemia inhibitory factor at a concentration of $1000 \mathrm{U} / \mathrm{mL}$ on feeders. Colonies were developed and trypsinized in about 3 days. The dissociated cells were then cultured in suspension in petri dishes. EBs were formed in about 2 days and continued to grow for a total of 5 days. EBs were then collected and imaged with the camera in live mode by an inverted microscope (A, B and C). The size of EBs was measured with the scale shown on the computer monitor and statistically analyzed $\left(D, n=10,{ }^{\# \#} p<0.05\right)$. EB, embryonic body; MEFsiPSC, mouse embryonic fibroblasts induced pluripotent stem cell; mAsiPSC, mouse astrocytes induced pluripotent stem cell.

the field of regenerative neuroscience is whether NSCs can efficiently generate neuronal phenotypes other than inhibitory olfactory bulb (OB) interneuron populations. Adult subventricular zone (SVZ) NSCs are primarily fated to generate nondopaminergic, gamma-amino butyric acid (GABA)-ergic OB interneurons (Lois and Alvarez-Buylla, 1994; Caldwell et al., 2001; Carleton et al., 2003; Jain et al., 2003). Our results demonstrate that mAsiPSCs differentiate into three germ layers in vivo (Fig. 3), meanwhile, NSCs derived from mAsiPSCs are multipotent and possess high potential for region-specific neuron differentiation (Fig. 4 and 5). Con- sidering the potential benefit of reprogramming excessive astrocytes during neurodegeneration into multipotent NSCs, which will differentiate into region-specific neurons to repair damaged neurons, mAsiPSCs will probably be a valuable strategy to better understand this process.

Interestingly, in our study, both of mAsiPSCs and MEFsiPSCs are from the reprogramming of their parental cells by ectopic expression of four transcription factors (Yamanaka factors). However, they differed in the size of embryonic bodies and differentiation potential. Low-passage mAsiPS cell line (mAsiPSCs No. 40) produced significantly smaller 


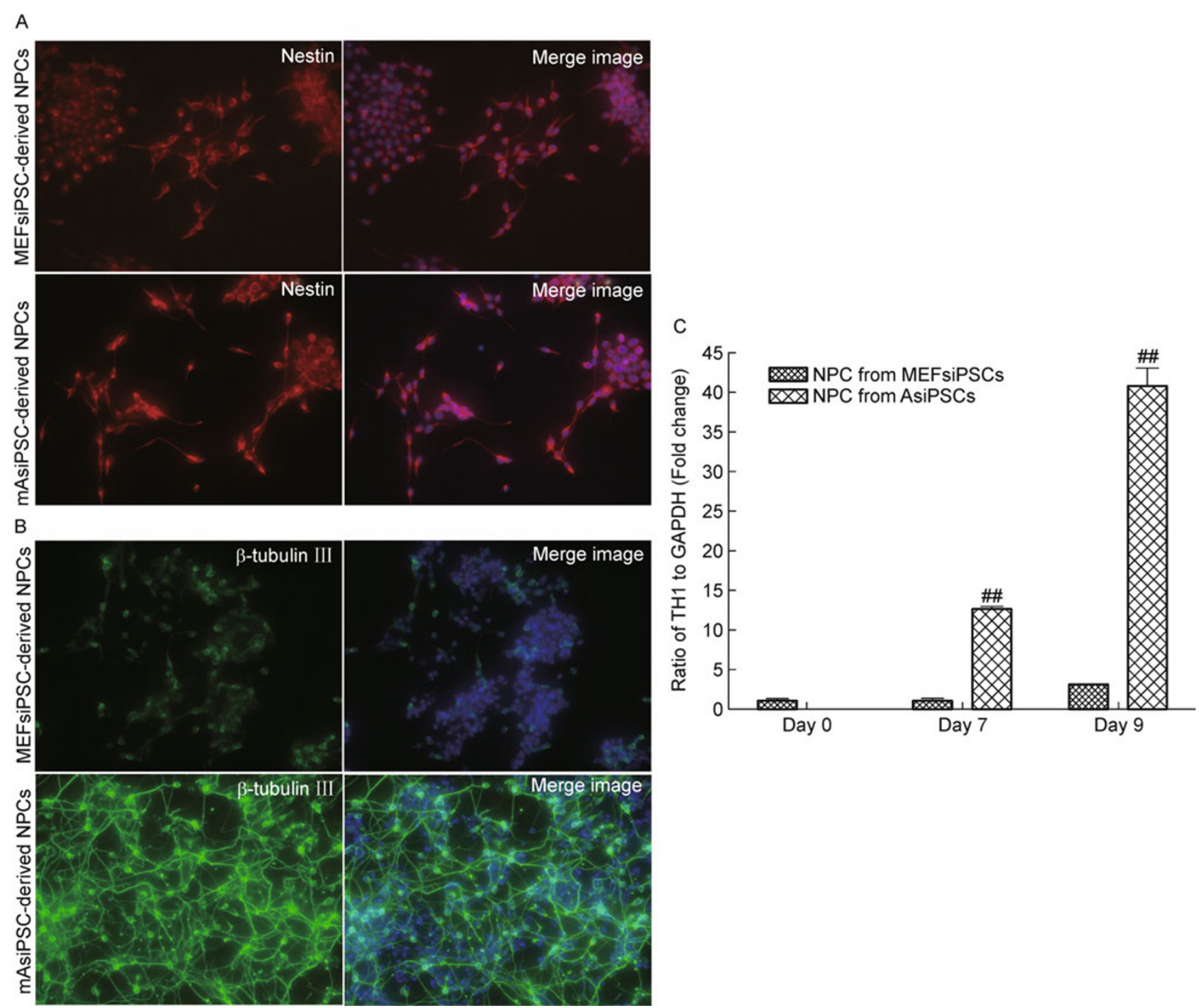

Figure 7. Comparison of neuronal differentiation between MEFsiPSCs and mAsiPSCs. The EBs from MEFsiPSCs and mAsiPSCs were plated onto adhesive tissue culture surface in the ES cell medium and then in serum-free ITSFn medium to screen nestin-positive cells after $24 \mathrm{~h}$. After 6-10 days culture in ITSFn medium, the cells were plated on collagen IV-coated coverslips and then subjected to immunostaining with monoclonal nestin antibody (Red) and nuclear staining with DAPI (Blue) (A). The cells cultured on collagen IV-coated coverslips were incubated under neuronal differentiation conditions for 7 days, and then subjected to immunostaining with polyclonal $\beta$-tubulin III antibody (Green) and nuclear staining with DAPI (Blue) (B). Cells cultured in DA neuron differentiation medium were collected at 0,7 th and 9 th days and then subjected to total mRNA extraction and real-time PCR analysis with mouse TH1 specific primers (C). ${ }^{\#} p<0.01$ vs MEFsiPSC-derived NPCs. Abbreviations are the same as in Fig.6.

embryonic bodies compared to MEFsiPSCs and mouse ES cells (Fig. 6), whereas another late-passage mAsiPS cell line (mAsiPSCs No. 47) showed less difference from others (data not shown), suggesting that continuous passaging of iPSCs abrogates some differences, which is consistent with the reported phenomena (Polo et al., 2010). Most notably, NSCs derived from mAsiPSCs including low-passage mAsiPSCs (No. 40) and late-passage mAsiPSCs (No. 47) possess a higher tendency to differentiate into neurons and dopaminer- gic neurons compared to MEFsiPSCs (Fig. 7). The molecular basis underlying the differentiation preference of the mAsiPSCs is not understood. Recently, detailed examination of a variety of iPSCs has shown that iPSCs retain some epigenetic imprints of the cell of origin, called an "epigenetic memory." (Baumann, 2010; Kim et al., 2010; Polo et al., 2010) Astrocytes are from the CNS and should retain the "epigenetic memory" of neuronal lineages, which likely endows mAsiPSCs with more potential for neuronal 
differentiation. A comparison of comprehensive epigenetic characterizations between mAsiPSCs and MEFsiPSCs will be required to elucidate whether some lineage-specific imprints will give mAsiPSCs more potential for the differentiation of original cell type and related cell types.

Taken together, we confirm that mouse astrocytes can be reprogrammed to pluripotency, and reprogrammed astrocytes possess a higher tendency to differentiate into related cell types. These results suggest that iPSCs from different origins may exhibit distinct differentiation potentials. This will be helpful in choosing the appropriate parental cell type for iPS cell generation.

\section{MATERIALS AND METHODS}

\section{Cells and cell culture}

Astrocytes were isolated from postnatal 7-day mouse brain cortices, as previously described (Ghorpade et al., 2003; Vitvitsky et al., 2006). Briefly, cortices of postnatal day 7 C57BL/6 mice were digested in $\mathrm{Ca}^{2+}$ - and $\mathrm{Mg}^{2+}$-free HBSS with $0.25 \%$ trypsin and $1 \mathrm{mM}$ EDTA, for $30 \mathrm{~min}$ at $37^{\circ} \mathrm{C}$ in tissue culture flasks on a rotary shaker at 150 rotation/min. Cells were washed and replated in DMEM/F12 containing $10 \%$ heat-inactivated fetal bovine serum (FBS), penicillin and streptomycin (Gibco, Rockville, Maryland) to generate primary cultures. Astrocyte purity was $>99 \%$, as determined by immunofluorescence using antibodies specific for glial fibrillary acidic protein (Santa Cruz Biotechnology, Santa Cruz, California) and $S 100 \beta$ (Sigma, St. Louis, Missouri). Antibodies specific to CD11b (Serotec, Raleigh, North Carolina) and galactocerebroside (Sigma) were used to identify microglia or oligodendrocytes, respectively. MEFs (CF-1) were dissected from embryos (12.5-13.5 days postcoitum) of CF1TM (Crl:CF1) mice (The Jackson Laboratory) and cultured in Dulbecco's Modified Eagle's Medium (ATCC, Cat No. 30-2002) with $15 \%$ FBS, penicillin and streptomycin. Plat-E cells (ATCC, RV-101) were maintained in DMEM, supplemented with $10 \% \mathrm{FBS}, 1 \mu \mathrm{g} / \mathrm{mL}$ puromycin, $10 \mu \mathrm{g} / \mathrm{mL}$ blasticidin, penicillin and streptomycin. ESC57BL/6 (ATCC, SCRC-1002 ${ }^{\mathrm{TM}}$ ) were cultured on mitotically arrested MEF (CF-1) (ATCC, SCRC-1040) with ES-DMEM (ATCC, SCRR2010) supplemented with $2.0 \mathrm{mM}$ L-Alanyl-L-Glutamine (ATCC, 302115), $0.1 \mathrm{mM}$ nonessential amino acids (ATCC 30-2116), $0.1 \mathrm{mM} 2-$ mercaptoethanol (Invitrogen Life Technologies, No. 21985), $1000 \mathrm{U} /$ $\mathrm{mL}$ mouse LIF (Chemicon, ESG1107) and 15\% FBS (ATCC, SCRR-30-2020).

\section{Retroviral packaging and viral infection}

Before the transduction, Plat-E cells were seeded at $3.6 \times 10^{6}$ cells per $100 \mathrm{~mm}$ culture dish. On the next day, pMXs-based retroviral vectors (Cell Biolabs, Inc. RTV-705-C) were introduced into Plat-E cells using calcium phosphate transfection reagent (Invitrogen) according to the manufacturer's recommendations. Cells were then incubated overnight at $37^{\circ} \mathrm{C}$ with $5 \% \mathrm{CO}_{2}$. Twenty-four hours after transduction, the medium was replaced. After another $24 \mathrm{~h}$, viruscontaining supernatants derived from these Plat-E cultures were filtered through a $0.45 \mu \mathrm{m}$ cellulose acetate filter (Schleicher \& Schuell) and supplemented with $10 \mu \mathrm{g} / \mathrm{mL}$ polybrene (Millipore). Mouse astrocytes seeded at $2 \times 10^{5}$ cells per well of 6 -well plates were incubated in the virus/polybrene-containing supernatants overnight. After infection, the cells were re-plated in $2 \mathrm{~mL}$ fresh medium.

\section{Immunostaining and alkaline phosphatase staining}

For immunostaining, cells were cultured on coverslips, fixed with $4 \%$ paraformaldehyde, and permeabilized with $0.2 \%$ Triton X-100 in PBS, and then blocked with $2 \%$ BSA in phosphate buffered saline (PBS) at room temperature for $2 \mathrm{~h}$. Cells were stained with primary antibodies against Nanog (Millipore, AB9220), stage-specific embryonic antigen1 (SSEA-1) (Millipore, No. 90230), tyrosine hydroxylase (Covance CRU Inc., No. 14921002), Nestin (Novus Biologicals, NB100-1604), MAP-2 (Millipore, AB5622), and $\beta$-tubulin III (Abcam ${ }^{\circledR}$, ab18207). After overnight primary antibody incubation, samples were washed with PBS and incubated with secondary antibodies (Invitrogen). Samples were also counterstained with DAPI (Invitrogen, 21490). Images were taken using Leica confocal microscope and regular fluorescence microscope. For alkaline phosphatase staining, ES cells or iPSCs were seeded on feeder layers pre-cultured on coverslips at low density and allowed to grow for 5 days in ES cell culture medium. Cells were fixed in $4 \%$ formaldehyde in PBS for $10-15 \mathrm{~min}$ at room temperature and then rinsed in PBS. They were stained with ELF ${ }^{\circledR}$ Phosphatase Detection Kit for Embryonic Stem Cells (ATCC, SCRR-3010) according to the manufacturer's guidelines.

\section{Teratoma formation and histological analysis}

Mouse ESCs or iPSCs were suspended at $1 \times 10^{7} \mathrm{cells} / \mathrm{mL}$ in DMEM containing 10\% FBS. SCID mice (Charles River Laboratories) were anesthetized with isoflurane. The cell suspension $\left(1 \times 10^{6}\right.$ cells $)$ was subcutaneously injected into each flank of SCID mice. Teratomas were surgically dissected from the mice 3-5 weeks after the injection. Samples were washed, fixed in PBS containing $4 \%$ formaldehyde, and embedded in paraffin. Sections were stained with hematoxylin and eosin (H\&E).

\section{Western blot analyses}

Western blot analysis was performed as previously described (Tian et al., 2008). The primary antibodies used were anti-Nestin (Rat-401) monoclonal antibody (sc-33677, Santa Cruz), anti- $\beta$-tubulin III polyclonal antibody (T2200, Sigma), and anti- $\beta$-actin monoclonal antibody (A5441, Sigma) as a loading control.

\section{Feeder-free EB culture of mouse ESCs, MEFsiPSCs and mAsiPSCs}

Mouse ESCs (SCRC-1002 ${ }^{\mathrm{TM}}$, ATCC, Manassas, VA, USA), MEFsiPSCs (SC201A, SBI, Mountain View, CA) and mAsiPSCs were cultured with ES-DMEM containing leukemia inhibitory factor at a concentration of $1000 \mathrm{U} / \mathrm{mL}$ to maintain the undifferentiated status of cells on feeders. Colonies were developed and the stem cells were trypsinized in about 3 days. The dissociated cells were then cultured in suspension in bacteriological grade culture dishes. EBs were formed in about 2 days and continued to grow for a total of 5 days. EBs were then collected and imaged with a camera in live mode under an inverted microscope. The size of EBs was measured with the scale shown on the computer monitor. 


\section{In vitro differentiation}

In vitro differentiation of mouse astrocyte-derived iPSCs was carried out as previously described (Lee et al., 2000) with modifications. Briefly, undifferentiated iPSCs were grown on gelatin-coated tissue culture plates in the presence of $1400 \mathrm{U} / \mathrm{mL}$ of leukemia inhibitory factor (LIF; GIBCO/BRL, Grand Island, NY) in ES cell medium consisting of knockout Dulbecco's minimal essential medium (DMEM; GIBCO/BRL) supplemented with 15\% FBS, 100 mM MEM nonessential amino acids, $0.55 \mathrm{mM}$ 2-mercaptoethanol, L-glutamine and antibiotics (all from GIBCO/BRL). To induce EB formation, the cells were dissociated into a single-cell suspension with $1 \times$ Trypsin-EDTA solution (GIBCO/BRL) in PBS and plated onto bacteriological grade culture dishes at a density of $2 \times 10^{4} \mathrm{cells} / \mathrm{cm}^{2}$ in the medium described above. The EBs were allowed to develop for four days and then plated onto adhesive tissue culture surface in the ES cell medium. After $24 \mathrm{~h}$ of culture, selection of nestin-positive cells was initiated by replacing the ES cell culture medium with serum-free ITSFn medium. After 6-10 days of selection, nestin-positive cells were then propagated in $\mathrm{N}_{2}$ medium (DMEM/F12 containing $1 \mathrm{~mL} \mathrm{~N}$ (GIBCO, Cat No. 17502-048), $500 \mathrm{ng} / \mathrm{mL}$ SHH (R\&D, Cat No. 461$\mathrm{SH}-025)$ and $100 \mathrm{ng} / \mathrm{mL}$ FGF8 (Peprotech, Cat No. 100-25). Specifically, the cells were dissociated with $1 \times$ Trypsin/EDTA, and plated on collagen IV-coated coverslips in 24-well plates at a concentration of $5 \times 10^{4}$ cells/well in $\mathrm{N}_{2}$ medium. After $24 \mathrm{~h}$, cells were cultured in DA neuron differentiation medium (DMEM/F12 supplemented with $\mathrm{N}_{2}$ and AA (200 $\mu \mathrm{M}$, Sigma, Cat No. 4403)). The cells were incubated under differentiation conditions for 7 days and then subjected to immunostaining and other experiments.

\section{RNA extraction and TaqMan real-time RT-PCR}

Total RNA was isolated with TRIzol Reagent (Invitrogen) and RNeasy Mini Kit (QIAGEN Inc., Valencia, CA). Assays-on-Demand primers for mouse tyrosine hydroxylase 1 (ID\#, Mm00447546_m1) and mouse GAPDH (ID\#, Mm03302249_g1) were purchased from Applied Biosystems Inc. (Foster City, CA). Real-time reversetranscription polymerase chain reaction (RT-PCR) was carried out using the one-step quantitative TaqMan Real-time RT-PCR system (Applied Biosystems Inc.). Tyrosine hydroxylase $1 \mathrm{mRNA}$ levels were determined and standardized with GAPDH as internal control.

\section{Statistical analyses}

Data were expressed as means $\pm S D$. The data were evaluated statistically by analysis of variance (ANOVA) followed by Tukey's test for paired observations. Significance was considered when $p<0.05$.

\section{ACKNOWLEDGEMENTS}

We kindly thank Dr. Terry D. Hexum for comments on the manuscript and thank Dr. Yunlong Huang, Dr. Hui Peng, Myhanh Che, Li Wu and Kristin M. Leland, who provided support for this work. Julie Ditter, Emilie Scoggins, Johna Belling, and Robin Taylor provided outstanding administrative and secretarial support. This work was supported in part by research grants from the National Institutes of Health: R01 NS 41858-01, R01 NS 061642-01, R21 MH 083525-01, P01 NS043985, and P20 RR15635-01 (JZ); the State of Nebraska,
DHHS-LB606 (JZ), Stem Cell-2010-10 (SD) and National Natural Science Foundation of China (Grant No. 81028007) (JZ).

\section{ABBREVIATIONS}

AP, alkaline phosphatase; CNS, central nervous system; DA, dopaminergic neurons; EBs, embryonic bodies; ESCs, embryonic stem cells; iPSCS, induced pluripotent stem cells; LIF, leukemia inhibitory factor; ITSFn, Insulin/Transferrin/Selenium/Fibronectin; mAsiPSCs, mouse astrocyte-derived iPSCs; MEFs, mouse embryonic fibroblasts; NPCs, neural progenitor cells; NSCs, neural stem cells; SCID, severe combined immunodeficient; SSEA-1, stagespecific embryonic antigen-1; TF4, four transcription factors; $\mathrm{TH}$, tyrosine hydroxylase

\section{REFERENCES}

Aasen, T., Raya, A., Barrero, M.J., Garreta, E., Consiglio, A., Gonzalez, F., Vassena, R., Bilić, J., Pekarik, V., Tiscornia, G., et al. (2008). Efficient and rapid generation of induced pluripotent stem cells from human keratinocytes. Nat Biotechnol 26, $1276-1284$.

Aoi, T., Yae, K., Nakagawa, M., Ichisaka, T., Okita, K., Takahashi, K., Chiba, T., and Yamanaka, S. (2008). Generation of pluripotent stem cells from adult mouse liver and stomach cells. Science 321 , 699-702.

Baumann, K. (2010). Stem cells: holding on to the memories. Nat Rev Mol Cell Biol 11, 601.

Blackburn, D., Sargsyan, S., Monk, P.N., and Shaw, P.J. (2009). Astrocyte function and role in motor neuron disease: a future therapeutic target? Glia 57, 1251-1264.

Caldwell, M.A., He, X., Wilkie, N., Pollack, S., Marshall, G., Wafford, K.A., and Svendsen, C.N. (2001). Growth factors regulate the survival and fate of cells derived from human neurospheres. Nat Biotechnol 19, 475-479.

Carey, B.W., Markoulaki, S., Hanna, J., Saha, K., Gao, Q., Mitalipova, M., and Jaenisch, R. (2009). Reprogramming of murine and human somatic cells using a single polycistronic vector. Proc Natl Acad Sci U S A 106, 157-162.

Carleton, A., Petreanu, L.T., Lansford, R., Alvarez-Buylla, A., and Lledo, P.M. (2003). Becoming a new neuron in the adult olfactory bulb. Nat Neurosci 6, 507-518.

Fawcett, J.W. (1997). Astrocytic and neuronal factors affecting axon regeneration in the damaged central nervous system. Cell Tissue Res 290, 371-377.

Ghorpade, A., Holter, S., Borgmann, K., Persidsky, R., and Wu, L. (2003). HIV-1 and IL-1 beta regulate Fas ligand expression in human astrocytes through the NF-kappa B pathway. J Neuroimmunol 141, 141-149.

Ghosh, Z., Wilson, K.D., Wu, Y., Hu, S., Quertermous, T., and Wu, J. C. (2010). Persistent donor cell gene expression among human induced pluripotent stem cells contributes to differences with human embryonic stem cells. PLoS One 5, e8975.

Hanna, J., Markoulaki, S., Schorderet, P., Carey, B.W., Beard, C., Wernig, M., Creyghton, M.P., Steine, E.J., Cassady, J.P., Foreman, R., et al. (2008). Direct reprogramming of terminally differentiated mature B lymphocytes to pluripotency. Cell 133, 250-264.

Hirsch, E.C., Breidert, T., Rousselet, E., Hunot, S., Hartmann, A., and Michel, P.P. (2003). The role of glial reaction and inflammation in 
Parkinson's disease. Ann N Y Acad Sci 991, 214-228.

Hu, Q., Friedrich, A.M., Johnson, L.V., and Clegg, D.O. (2010). Memory in induced pluripotent stem cells: reprogrammed human retinal-pigmented epithelial cells show tendency for spontaneous redifferentiation. Stem Cells 28, 1981-1991.

Jain, M., Armstrong, R.J., Tyers, P., Barker, R.A., and Rosser, A.E. (2003). GABAergic immunoreactivity is predominant in neurons derived from expanded human neural precursor cells in vitro. Exp Neurol 182, 113-123.

Johe, K.K., Hazel, T.G., Muller, T., Dugich-Djordjevic, M.M., and McKay, R.D. (1996). Single factors direct the differentiation of stem cells from the fetal and adult central nervous system. Genes Dev 10, 3129-3140.

Kim, J.B., Greber, B., Araúzo-Bravo, M.J., Meyer, J., Park, K.I., Zaehres, H., and Schöler, H.R. (2009a). Direct reprogramming of human neural stem cells by OCT4. Nature 461, 649-3.

Kim, J.B., Sebastiano, V., Wu, G., Araúzo-Bravo, M.J., Sasse, P., Gentile, L., Ko, K., Ruau, D., Ehrich, M., van den Boom, D., et al. (2009b). Oct4-induced pluripotency in adult neural stem cells. Cell 136, 411-419.

Kim, J.B., Zaehres, H., Araúzo-Bravo, M.J., and Schöler, H.R. (2009c). Generation of induced pluripotent stem cells from neural stem cells. Nat Protoc 4, 1464-1470.

Kim, J.B., Zaehres, H., Wu, G., Gentile, L., Ko, K., Sebastiano, V., Araúzo-Bravo, M.J., Ruau, D., Han, D.W., Zenke, M., et al. (2008). Pluripotent stem cells induced from adult neural stem cells by reprogramming with two factors. Nature 454, 646-650.

Kim, K., Doi, A., Wen, B., Ng, K., Zhao, R., Cahan, P., Kim, J., Aryee, M.J., Ji, H., Ehrlich, L.I., et al. (2010). Epigenetic memory in induced pluripotent stem cells. Nature 467, 285-290.

Lee, S.H., Lumelsky, N., Studer, L., Auerbach, J.M., and McKay, R.D. (2000). Efficient generation of midbrain and hindbrain neurons from mouse embryonic stem cells. Nat Biotechnol 18, 675-679.

Lois, C., and Alvarez-Buylla, A. (1994). Long-distance neuronal migration in the adult mammalian brain. Science 264, 1145-1148.

Moon, J.H., Yoon, B.S., Kim, B., Park, G., Jung, H.Y., Maeng, I., Jun, E.K., Yoo, S.J., Kim, A., Oh, S., et al. (2008). Induction of neural stem cell-like cells (NSCLCs) from mouse astrocytes by Bmi1. Biochem Biophys Res Commun 371, 267-272.

Pereira, C.F., Terranova, R., Ryan, N.K., Santos, J., Morris, K.J., Cui, W., Merkenschlager, M., and Fisher, A.G. (2008). Heterokaryonbased reprogramming of human B lymphocytes for pluripotency requires Oct4 but not Sox2. PLoS Genet 4, e1000170.

Polo, J.M., Liu, S., Figueroa, M.E., Kulalert, W., Eminli, S., Tan, K.Y., Apostolou, E., Stadtfeld, M., Li, Y., Shioda, T., et al. (2010). Cell type of origin influences the molecular and functional properties of mouse induced pluripotent stem cells. Nat Biotechnol 28, 848-855.

Ridet, J.L., Malhotra, S.K., Privat, A., and Gage, F.H. (1997). Reactive astrocytes: cellular and molecular cues to biological function. Trends Neurosci 20, 570-577.

Rodríguez, J.J., Olabarria, M., Chvatal, A., and Verkhratsky, A. (2009). Astroglia in dementia and Alzheimer's disease. Cell Death Differ 16, 378-385.

Sher, F., Boddeke, E., and Copray, S. (2011). Ezh2 expression in astrocytes induces their dedifferentiation toward neural stem cells. Cell Reprogram 13, 1-6.

Stadtfeld, M., Brennand, K., and Hochedlinger, K. (2008). Reprogramming of pancreatic beta cells into induced pluripotent stem cells. Curr Biol 18, 890-894.

Studer, L., Tabar, V., and McKay, R.D. (1998). Transplantation of expanded mesencephalic precursors leads to recovery in parkinsonian rats. Nat Neurosci 1, 290-295.

Takahashi, K., Okita, K., Nakagawa, M., and Yamanaka, S. (2007). Induction of pluripotent stem cells from fibroblast cultures. Nat Protoc 2, 3081-3089.

Takahashi, K., and Yamanaka, S. (2006). Induction of pluripotent stem cells from mouse embryonic and adult fibroblast cultures by defined factors. Cell 126, 663-676.

Tian, C., Gao, P., Zheng, Y., Yue, W., Wang, X., Jin, H., and Chen, Q. (2008). Redox status of thioredoxin-1 (TRX1) determines the sensitivity of human liver carcinoma cells (HepG2) to arsenic trioxide-induced cell death. Cell Res 18, 458-471.

Utikal, J., Maherali, N., Kulalert, W., and Hochedlinger, K. (2009). Sox2 is dispensable for the reprogramming of melanocytes and melanoma cells into induced pluripotent stem cells. J Cell Sci 122, 3502-3510.

Vicario-Abejón, C., Johe, K.K., Hazel, T.G., Collazo, D., and McKay, R.D. (1995). Functions of basic fibroblast growth factor and neurotrophins in the differentiation of hippocampal neurons. Neuron 15, 105-114.

Vitvitsky, V., Thomas, M., Ghorpade, A., Gendelman, H.E., and Banerjee, R. (2006). A functional transsulfuration pathway in the brain links to glutathione homeostasis. J Biol Chem 281, 35785-35793.

Wakayama, T., Tabar, V., Rodriguez, I., Perry, A.C., Studer, L., and Mombaerts, P. (2001). Differentiation of embryonic stem cell lines generated from adult somatic cells by nuclear transfer. Science 292, 740-743.

Ye, Z., Zhan, H., Mali, P., Dowey, S., Williams, D.M., Jang, Y.Y., Dang, C.V., Spivak, J.L., Moliterno, A.R., and Cheng, L. (2009). Humaninduced pluripotent stem cells from blood cells of healthy donors and patients with acquired blood disorders. Blood 114, 5473-5480.

Yu, J., Vodyanik, M.A., Smuga-Otto, K., Antosiewicz-Bourget, J., Frane, J.L., Tian, S., Nie, J., Jonsdottir, G.A., Ruotti, V., Stewart, R., et al. (2007). Induced pluripotent stem cell lines derived from human somatic cells. Science 318, 1917-1920. 